\title{
The Nature of the Meteorological Fluctuations in Clouds ${ }^{1}$
}

\author{
BERNICE ACKERMAN \\ The University of Chicago, Ill. \\ (Manuscript received 11 May 1966, in revised form 8 September 1966)
}

\begin{abstract}
As in-cloud measurements have accumulated it has become increasingly apparent that clouds are markedly non-uniform in structure. This is demonstrated by sizable and rapid variations in the horizontal for almost all meteorological variables. A systematic study was made of the fluctuations in measurements obtained in hurricane clouds to establish whether they could be ascribed to a random process or whether they exhibited some spatial order.

Variance spectrum analysis of continuous measurements of temperature, liquid-water content and airspeed for 49 cloud areas indicated that, in most cases, the variations were not random and that, in addition to the cloud scale, there were non-random components of smaller size. With considerable consistency, particularly in turbulent convection, the spectra indicated the existence of two frequency "domains" within which one or more dominant modes of activity occurred. These domains extended a) from 1.8-4 cycle mile-1 with peaks most frequent around $2.5 \mathrm{cycle}^{-1} \mathrm{mil}^{-1}$, and b) from $4.5-9 \mathrm{cycle}^{-1} \mathrm{mile}^{-1}$ with peaks occurring most often between 5 and 6 cycle mile ${ }^{-1}$.
\end{abstract}

\section{Introduction}

An outstanding characteristic of cloud structure is its "graininess," a feature which has been manifested again and again as fluctuations in meteorological measurements made while flying through cloudy areas. This characteristic sets a cloud apart from its environment with a definity equal to that of its "visual" properties. The many measurements collected over the past fifteen years or so have established the heterogeneity of convective cloud structure and, although far fewer in number, observations in stable clouds indicate that these, too, are non-uniform in space.

The scales and magnitudes of the variations found in a group of measurements may depend somewhat on the manner of measurement. But evidently the fluctuating characteristic does not since this has been reported for measurements made by a variety of techniques and for most meteorological parameters. The existence of inhomogeneities has usually been acknowledged but analyses of in-cloud measurements have concentrated on the more general cloud features by considering smoothed space distributions and/or "characteristic" values such as cloud averages or maxima. There have been a few exceptions, most notably the studies dealing with small-scale irregularities in the velocity field as related to airplane response.

One must eventually ask if these bothersome variations in space, in distance frequently short with respect to cloud size, and in amplitude small with respect to the average, are important in the over-all cloud

\footnotetext{
${ }^{1}$ Research supported by the Atmospheric Sciences Program, National Science Foundation, NSF Grants G22292 and GP3881.
}

picture. Can we adequately understand the basic cloud processes without the complications which they imply?

Convective clouds tend to occur on discrete scales associated with synoptic scale disturbances or, in undisturbed weather, organized in geometric formations with scales of 10-100 miles and/or as individual cumulus and aggregates ranging in size from 1-10 miles. Examination of continuously-recorded measurements leaves one with the impression that there may be smaller scales of organization. In many parameters, the variations appear to occur as sub-cloud sized cells upon which are superimposed fluctuations of still smaller size, suggesting one or more sub-cloud scales of activity.

The research reported herein dealt with just this point, i.e., whether or not such sub-cloud scales do exist. The premise was that the fluctuations reflect the action of a number of physical-chemical processes ranging from molecular to synoptic in scale and that some insight into the nature and interaction of these processes might be obtained from a scale analysis of the within-cloud variations in meteorological parameters. From a purely practical point of view, not only would information of this kind be useful in planning observational and measurement programs but it would aid in the interpretation of so-called characteristic values.

The study was designed to seek answers to the following questions:

1) Are the fluctuations in meteorological parameters observed as a plane flies through a cloud, random variations or are they regular in the sense that certain space scales dominate?

2) If they are not random, are certain scales "preferred" in clouds of a given type? 


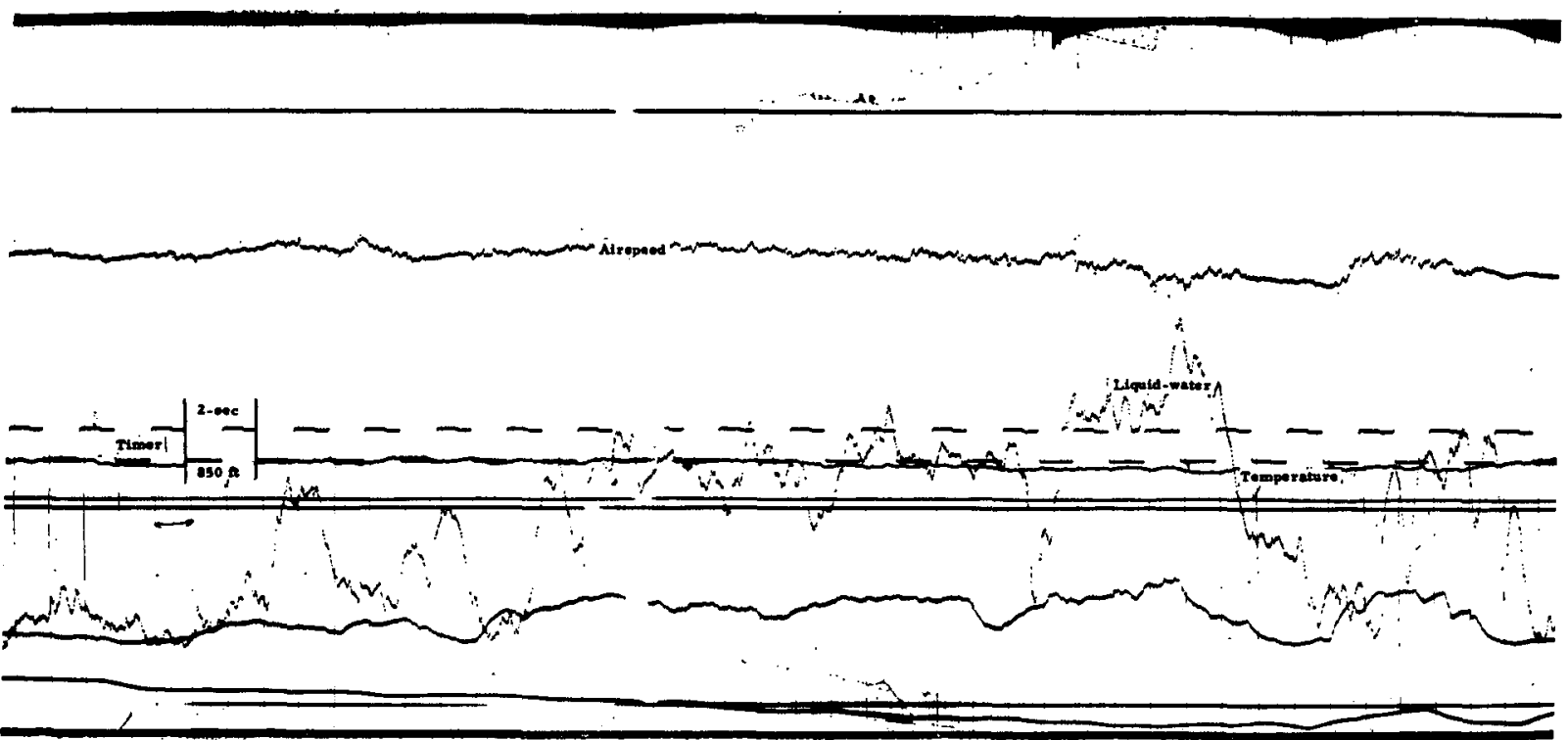

FIG. 1. Oscillograph record obtained in a convective band.

Continuous in-cloud measurements were subjected to mathematical-statistical analyses which yielded normalized variance spectra. Spectral analysis is directly concerned with fluctuations in time and space series and permits an objective study of these seemingly intractable variations. It yields a statistical description of the irregularities from which certain inferences can be drawn about the distribution in real space.

\section{The data}

During the 1956-1958 field operations of the National Hurricane Research Project, The University of Chicago, under contract to the U. S. Weather Bureau, provided, maintained and operated certain airborne instruments for the continuous measurement of variables pertinent to cloud physics studies in hurricanes. These measurements were recorded on an analogue recorder which provided essentially continuous data throughout flights into hurricanes, broken only as necessary for film change.

a) The measurements. Three parameters were considered in the present study: liquid-water content, temperature, and, indirectly, turbulence in the velocity field. Details of the pertinent instrument and recording systems on the B-50 airplanes used by the Hurricane Project may be found in a report by Braham and Neil (1957) and are briefly described below.

The liquid-water content measurements were obtained with a paper-tape, liquid-water content meter designed by Warner and Newnham (1952) but considerably modified by members of the Cloud Physics Laboratory. This instrument measures the electrical resistance across an electrolytically-treated paper tape which has been exposed to the airstream; the conductivity of the paper is a function of the amount of water which was absorbed by it during exposure.
Temperature was measured with a copper-constantan thermocouple mounted in a reverse-flow housing. This housing required the air to make a $180 \mathrm{deg}$ turn, thus minimizing the possibility that the thermocouple might be wetted by cloud droplets. The air reaching the thermocouple was subjected to aerodynamic heating but the measured temperature was corrected to ambient by an empirically determined function of airspeed.

Lacking direct measurement of the velocity field on a scale small enough to be of use in studying variations in clouds, sensitive measurements of airspeed were used as an indicator of turbulence. Studies by the National Advisory Committee for Aeronautics some years ago showed that the accelerations imposed on an airplane flying through a turbulent area are manifested as rapid airspeed fluctuations and that these, in turn, are a measure of the horizontal components of the turbulent eddies (Tolefson, 1945). The flight procedures were to fly on automatic pilot insofar as possible with constant power-settings. The variations due to the auto-pilot adjustments should be slow relative to the wavelength regime of interest and the fluctuations in the airspeed measurements are most likely due to variations in the velocity field. The measurements were obtained using a strain gage differential pressure transducer mounted in close proximity to a standard pitot head.

The outputs of the temperature, liquid-water content and airspeed instruments were continuously recorded on a Heiland oscillograph recorder operated with a paper speed of about $1 \mathrm{~cm} \mathrm{sec}^{-1}$. At the usual airplane speed, $1 \mathrm{~cm}$ of paper corresponded to about $125 \mathrm{~m}$ displacement in space.

An example of the records obtained in hurricane clouds (in this case an active convective cloud) is shown in Fig. 1. The appearance of this record is little different 
from that of records obtained in active convection in other locales and in other weather systems. The nonuniform nature of the cloud is apparent in the fluctuations in the curves. The amplitudes of the variations in the original record are a function of the calibration; their true magnitudes are more accurately evaluated from the reduced series given in Fig. 2.

The final series were composed of ambient values of the three cloud parameters. Temperatures were referred to the average altitude for the traverse using the moistadiabatic lapse rate. Information concerning the vertical distribution of water is sketchy but does indicate that any adiabatic assumption would be greatly in error, particularly in hurricane clouds (Ackerman, 1963). Therefore, no adjustment was made in water content (or airspeed) for possible variations in altitude. This amounted to assuming that there was no vertical gradient in the variable in the two or three hundred feet of vertical displacement during a cloud traverse.

Although the records were continuous for long periods, individual series covered relatively short sections during which the airplane passed through well-defined cloud areas. It should be pointed out that the measurements are both time and space dependent. To simplify the analysis, it was assumed that during the time required to traverse a cloud area the changes were small and that, in a given series, the measurements were only space dependent. This assumption is reasonable in view of the fact that the time elapsed during a single series was only two or three minutes.

b) The clouds. The data were obtained on five flights made by the Hurricane Project B-50 airplanes into three different storms during 1957 and 1958. In two hurricanes the data were obtained at the times of their most active intensification and again just as they were reaching their peak intensity. The fifth flight was through a storm in its mature stage as it was filling slowly.

Radar and cloud photographs as well as visual observations from many reconnaissance flights into hurricanes over the past few years indicate that the cloud distributions are complex, change during the life history of a storm, and may vary from storm to storm. In general, however, well-spaced convective cloud bands or lines are embedded in widespread stratiform cloud decks occurring at several levels. It is my impression that most of these broken cloud decks are composed of remnants of the large convective developments.

From previous experience with records of this kind it was possible to distinguish between measurements characteristic of convective clouds and those characteristic of stratiform clouds. This coupled with what radar photographs and visual observations were at hand formed the basis for the selection of sections of record to be used in the analysis. Most of the sections chosen were from active convective cloud regions. A few cases of stratus and light rain were included, almost all of

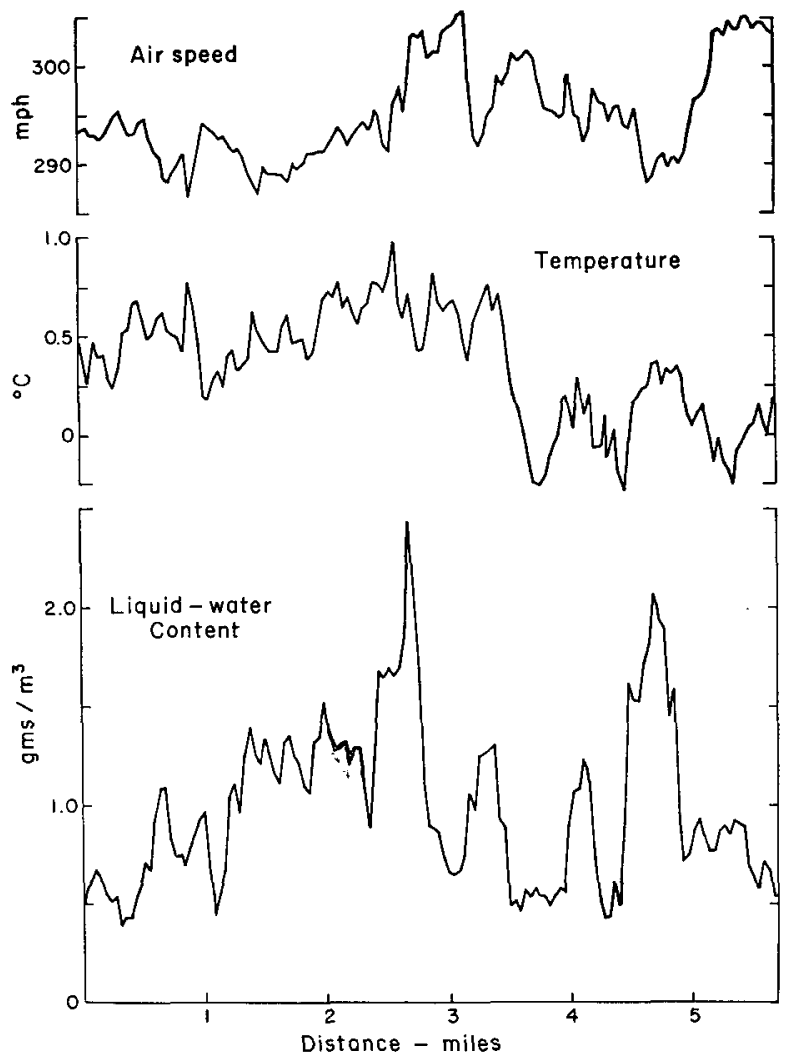

FIG. 2. Water content, temperature, and airspeed series evaluated from the record shown in Fig. 1. Only the first $3.5 \mathrm{mi}$ of the traverse is shown in Fig. 1.

which were either extensions from a convective band or connections between convective areas. In addition, a few cloud areas having characteristics somewhere in between the two extremes were also included. These have been called cellular rain.

Most of the data were collected at altitudes around $16,000 \mathrm{ft}$, some at about $13,000 \mathrm{ft}$ and still less at about $10,000 \mathrm{ft}$. On occasion, the traverses were made in the vicinity of the freezing level, but the accuracy of the temperature and airspeed measurements were not affected, nor, as far as can be detected, were the water content measurements. Since ambient temperatures were almost always warmer than $-3 \mathrm{C}$, and some aerodynamic warming was likely in the vicinity of the exposure slit of the paper-tape housing, there probably was no icing of any consequence. Areas in which solid. precipitation of any kind was recorded, reported, or suspected were not included in this study.

The flights were usually made on a standard cloverleaf pattern through the hurricane. Thus, in general, the traverses were made across the band and wind field (roughly 50 to $90 \mathrm{deg}$ ). In just a few instances the paths were along or diagonally across the band.

Most of the series were between 5 and $12 \mathrm{mi}$ in length, with a few extending for distances up to $18 \mathrm{mi}$; the average length was $8.5 \mathrm{mi}$. In about two-thirds of the 
TABLE 1. Meteorological and dimensional variables of the sample.

\begin{tabular}{|c|c|c|c|}
\hline & Convection & $\underset{\text { rain }}{\text { Cellular }}$ & Stratus \\
\hline Data Interval & \multicolumn{3}{|c|}{ Number of series } \\
\hline $\begin{array}{r}200 \mathrm{ft} \\
85 \mathrm{ft}\end{array}$ & $\begin{array}{l}17 \\
10\end{array}$ & $\begin{array}{l}7 \\
6\end{array}$ & $\begin{array}{l}7 \\
2\end{array}$ \\
\hline \multicolumn{4}{|l|}{ Altitude } \\
\hline $\begin{array}{l}10,000 \mathrm{ft} \\
13,000 \mathrm{ft} \\
16,000 \mathrm{ft}\end{array}$ & $\begin{array}{r}5 \\
5 \\
17\end{array}$ & $\begin{array}{r}0 \\
2 \\
11\end{array}$ & $\begin{array}{l}0 \\
0 \\
9\end{array}$ \\
\hline \multicolumn{4}{|c|}{ Distance from center } \\
\hline $\begin{array}{c}<40 \mathrm{nmi} \\
40-90 \mathrm{n} \mathrm{mi}\end{array}$ & $\begin{array}{r}18 \\
9\end{array}$ & $\begin{array}{r}12 \\
1\end{array}$ & $\begin{array}{l}8 \\
1\end{array}$ \\
\hline & \multicolumn{3}{|c|}{ Length of series ( $n$ mi) } \\
\hline $\begin{array}{l}\text { Range } \\
\text { Average }\end{array}$ & $\begin{array}{c}4.5-15.7 \\
8.1\end{array}$ & $\begin{array}{c}3.9-18.8 \\
9.6\end{array}$ & $\begin{array}{c}4.8-15.9 \\
8.6\end{array}$ \\
\hline Water content & \multicolumn{3}{|c|}{ Sample averages* } \\
\hline $\begin{array}{l}\text { Series mean } \\
\text { Variance }\end{array}$ & $\begin{array}{l}1.04 \\
0.57\end{array}$ & $\begin{array}{l}0.50 \\
0.06\end{array}$ & $\begin{array}{l}0.26 \\
0.03\end{array}$ \\
\hline \multicolumn{4}{|l|}{ Temperature } \\
\hline $\begin{array}{l}\text { Series mean } \\
\text { Variance } \\
\text { Airspeed }\end{array}$ & $\begin{array}{l}2.16 \\
0.22\end{array}$ & $\begin{array}{r}-0.67 \\
0.06\end{array}$ & $\begin{array}{r}-1.97 \\
0.06\end{array}$ \\
\hline $\begin{array}{l}\text { Series mean } \\
\text { Variance }\end{array}$ & $\begin{array}{l}280.0 \\
41.39\end{array}$ & $\begin{array}{l}271.1 \\
16.76\end{array}$ & $\begin{array}{l}268.6 \\
12.30\end{array}$ \\
\hline
\end{tabular}

* The variances and mean values of the variable for individual series averaged over the sample.

cases the data points were separated by $0.5 \mathrm{sec}$ (about $200 \mathrm{ft}$ ); in the rest they were separated by $0.2 \mathrm{sec}$ (about $85 \mathrm{ft}$ ). In Table 1 is a summary of some of the cloud and traverse characteristics for the three cloud types.

\section{Variance spectrum techniques}

Spectrum analysis is based on a relationship, originally developed in the early 1930's, in which the spectral function is expressed as the Fourier transform of the auto-covariance function. Later work by a number of mathematicians and statisticians adapted the theory to finite, non-continuous series leading to approximation equations which have been applied to a number of geophysical problems. This technique has, however, seldom been used in problems dealing with cloud structure.

Briefly, the analysis considers a series as composed of an infinite number of oscillations, with continuously distributed frequencies and randomly distributed phases, and then seeks the average contribution to the variance of the series from a finite number of frequency bands. For finite series the estimates of these contributions are subject to sampling variability and may be assigned a statistical reliability based on the length of the series and the width of the frequency bands.
Since the prime objective was to search for modes, the normalized spectrum, which gives the relative contribution to the variance, was as pertinent as the variance spectrum itself. Moreover, comparisons between normalized spectra, which have a common, nondimensional "intensity" of unity may be made for different meteorological parameters as well as different cloud types. Thus, the normalized spectral densities, rather than the spectral estimates, were computed.

The computations were based on the Tukey-Hanning formulations and the statistical significance of the estimates on the tests developed by Tukey. (Complete description and discussion of the Tukey-Hanning approximations and of the statistical tests may be found in a number of sources, e.g., Blackman and Tukey (1958), and will not be repeated here.) The calculations yielded the normalized density function $U(k)$, in units of (cycle/mile $)^{-1}$ for a specified number of space frequency bands, as a function of the wave number, $k\left(\mathrm{cy} \mathrm{mi}^{-1}\right)$, at the center of the band. The product of $U(k)$ and the bandwidth gives the relative contribution to the variance from the band.

The frequency range extended, nominally, from zero to about $13 \mathrm{cy} \mathrm{mi} \mathrm{m}^{-1}$ in cases where the data interval was $200 \mathrm{ft}$ and to about $32 \mathrm{cy} \mathrm{mi}^{-1}$ when it was $85 \mathrm{ft}$. The calculations were carried out for resolutions (i.e., bandwidths) of $0.2 \mathrm{cy} \mathrm{mi} \mathrm{m}^{-1}$ except in a few cases in which wider bands had to be used because of short series lengths. In the latter, estimates were obtained for the narrowest band which would permit at least 5 degrees of freedom for statistical testing. Resolution of $0.2 \mathrm{cy} \mathrm{mi} \mathrm{mi}^{-1}$ and greater is not adequate to separate modes at the low frequencies. Thus, the range that could be studied effectively extended upwards from $0.6 \mathrm{cy}$ $\mathrm{mi}^{-1}$.

A peak in the spectrum indicates that oscillations having frequencies in that band contribute more than their share of the total variance, provided it is not due to sampling variations. To establish the reality of spectral peaks, they were tested for non-randomness around an estimated red noise spectrum (Ward and Shapiro, 1961; Gilman et al., 1963), using $\chi^{2}$ tests developed by Tukey (1949). The underlying red noise spectrum, the basic shape of which is dictated by persistence, was "fitted" to each spectrum by eye, with the supplementary aid afforded by a crude-resolution $\left(1 \mathrm{cy} \mathrm{mi}{ }^{-1}\right)$ spectrum. The degrees of freedom varied from traverse to traverse but were always greater than five.

The computed spectra, with few exceptions, had the large values in the low wave numbers which are characteristic of the red noise spectrum and which are due to some form of persistence in the original data. This was not unexpected since it was realized that in many of the series there would be at least one important component, that comparable to the cloud or band itself, which could not be resolved. Moreover, since most of the passes were made radially with respect to the sym- 
metry of the hurricane, the large scale gradients in temperature and wind also were contained in the series.

A number of methods (e.g., pre-whitening, low-pass filtering, polynomial regression) have been proposed to remove or minimize the effects of this type of nonstationarity on the spectrum. The results of rather extensive preliminary studies indicated that, in view of the restrictions imposed by the basic data, the limited gains did not warrant the computational investment, particularly since most of the procedures introduced additional complications in the final interpretation of the results. Therefore, untransformed series were used throughout.

\section{Results}

The computed normalized spectra varied in detail, but not in general features. A typical case is shown in Fig. 3. Although plotted as a simple polygon, a rectangular polygon would be a more accurate representation since the estimates are for the average contribution from the band centered at the wave number indicated by the dots. Also shown are the estimated underlying "true" spectrum and the confidence limits used in determining statistically significant peaks.

It is apparent from this sample case that the spectra were not simple. Peaks did occur, but in numbers which discourage immediate and simple interpretation. Generally there were large contributions from the first two or three wave bands, decreasing rapidly in the region of $k<1$. The decrease in spectral density continued at larger wave numbers, but far more gradually. Superimposed upon this general decrease were irregular oscillations which, by virtue of pronounced minima as well as peaks, tended to break the spectrum into two regions: one extending from 1-2 $\mathrm{cy} \mathrm{mi}{ }^{-1}$ to 4-5 $\mathrm{cy} \mathrm{mi}^{-1}$, the other from about $5 \mathrm{cy} \mathrm{mi}^{-1}$ to $9-10 \mathrm{cy} \mathrm{mi}^{-1}$.

The trend component, i.e., the amplification in the first few wave bands, tended to be greatest in the temperature spectra for radial traverses, particularly those through wall clouds. There were a number of occasions, usually in active convection, in which the trend component was pronounced in the airspeed and water content spectra also. For all parameters and especially water content the trend component tended to be greatest in active convective bands and least in stratus or light rain. It was often apparent from the appearance of the original series that the large contributions in the first two or three wave bands were due not to long trend (although for convenience it will be referred to as the trend component) but to unresolved, long-wave components.

There was considerable disparity in the spectra; this is not surprising considering the probable range in cloud type and age and the random manner in which the clouds were intercepted. However, certain patterns seemed to repeat and the three spectra for any one cloud tended to have a great deal of similarity. Often

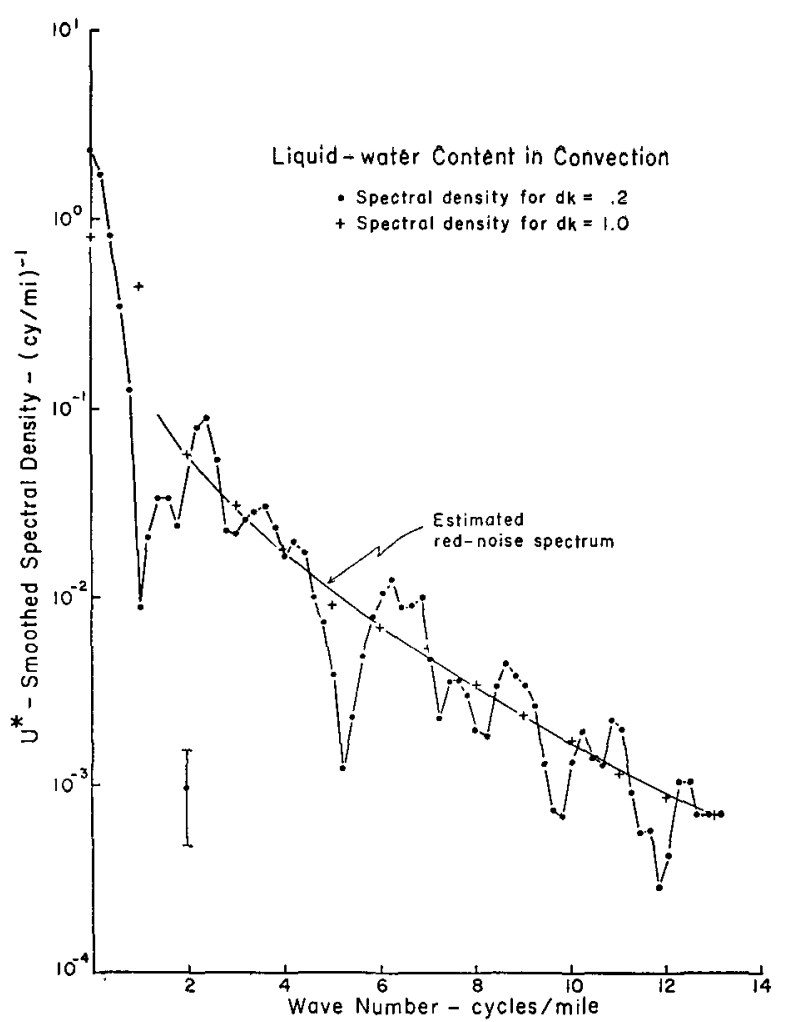

FIG. 3. Normalized spectrum computed for resolution of 0.2 cy $\mathrm{mi}^{-1}$ and estimated underlying red noise spectrum. The 90 per cent confidence limits are shown in lower left.

the modal frequencies were identical although their relative contributions might not be.

The averaging of the individual spectra would poorly serve the objectives of the study (the identification of modes) since averaging tends to smooth. An alternative approach was used involving the determination of the number of spectra on which statistically significant modes were found in given intervals of wave numbers. A significant peak was one which exceeded the upper 90 per cent confidence interval computed for the underlying red noise spectrum. In making the count of the occurrence of peaks, class intervals of 0.1 in $\log k$ was used for $k \geq 1.6 \mathrm{cy} \mathrm{mi}-1$ and intervals of $0.2 \mathrm{in} \log k$ for the range $0.6<k<1.6 \mathrm{cy} \mathrm{mi}{ }^{-1}$. The intervals were based on $\log k$, rather than on $k$ itself, because they yield more realistic ranges in wavelength, particularly at the high wave numbers. The larger interval was used at the lower frequency because the resolution in the spectrum was too low to give much significance to the narrower interval.

Histograms giving the number of spectra in which peaks occurred in certain wave bands for each of the three cloud types are shown in Figs. 4 to 6 . These histograms do not extend beyond wave number $12.6 \mathrm{cy} \mathrm{mi}^{-1}$ because over half the spectra were truncated at slightly higher frequencies; they do not include wave numbers 

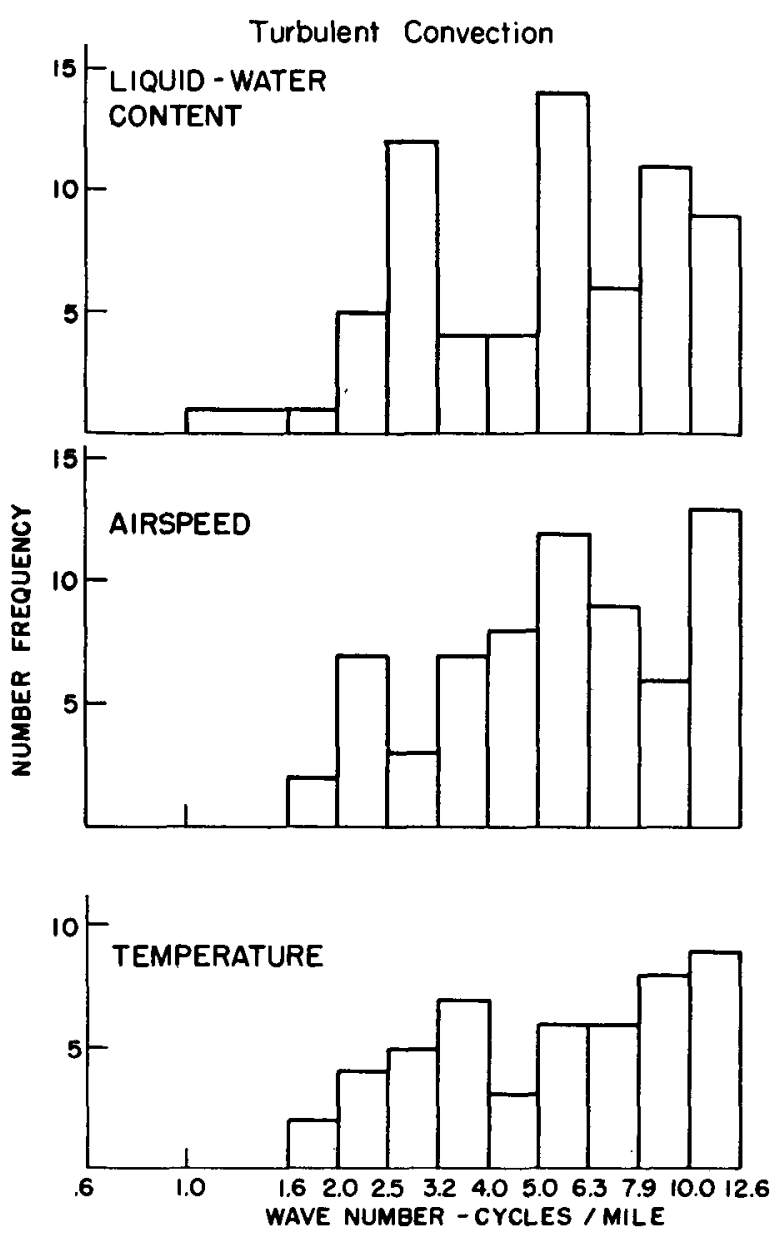

Fig. 4. Histograms showing number of spectra for convective bands having a peak significant at the 10 per cent level in the specified interval of wave number.

below $0.6 \mathrm{cy} \mathrm{mi}^{-1}$ because, as noted above, lower frequencies could not be resolved in the spectra.

The low incidence of peaks in the wave numbers less than 2 cy $\mathrm{mi}^{-1}$ may be due to inadequate resolution in the presence of important very-low frequency components. Careful study of the individual spectra suggest that perhaps 80 per cent of the series may have contained a component with wavelength between one-third of a mile and one mile which contributed importantly to the variance. The large numbers of cases between 10 and $12.6 \mathrm{cy} \mathrm{mi}^{-1}$ are suspect because they may include contributing oscillations of smaller wavelength due to aliasing. A study of 25 traverses whose spectra extended to roughly $30 \mathrm{cy} \mathrm{mi}^{-1}$ indicated that the frequencies shown in the histograms are valid for airspeed and temperature but that for water content series they are more representative of the larger range from 10 to 20 cy $\mathrm{mi}^{-1}$.

It is obvious from Figs. 4 to 6 that significant peaks in the spectra were frequent, thus indicating that, at least for individual traverses, the "patchiness" reflected in the irregularities of the individual fields, occurred on certain preferred scales. Moreover, there seemed to be a fair degree of consistency from cloud to cloud, particularly among convective clouds. Most of the histograms are bi-modal, suggesting, as did the individual spectra, the existence of two scales of patchiness.

Since primary interest was in convective developments, the selection of cases emphasized this type of cloud. The final sample of convective cases (27) is large enough to reveal preferential scale sizes if they exist and is also large enough to be fairly representative. The samples for cellular rain and stratus (13 and 9 cases, respectively) are quite small, perhaps too small to reveal characteristic scales if they do occur.

a) Convective bands. Preferred modal frequencies were approximately the same for all three parameters, but the consistency among cases was greatest for liquid water content and least for temperature. The peak in the longer waves occurred primarily between 2 and 3 cy $\mathrm{mi}^{-1}$ in liquid water and airspeed spectra and, more generally, between 2.5 and $4 \mathrm{cy} \mathrm{mi}-1$ in temperature spectra. The peak in the shorter wave regime occurred between 5 and $6 \mathrm{cy} \mathrm{mi}^{-1}$ with a fairly high degree of persistence in the water content and airspeed spectra. However, a preferred modal position was not found in this domain for temperature.
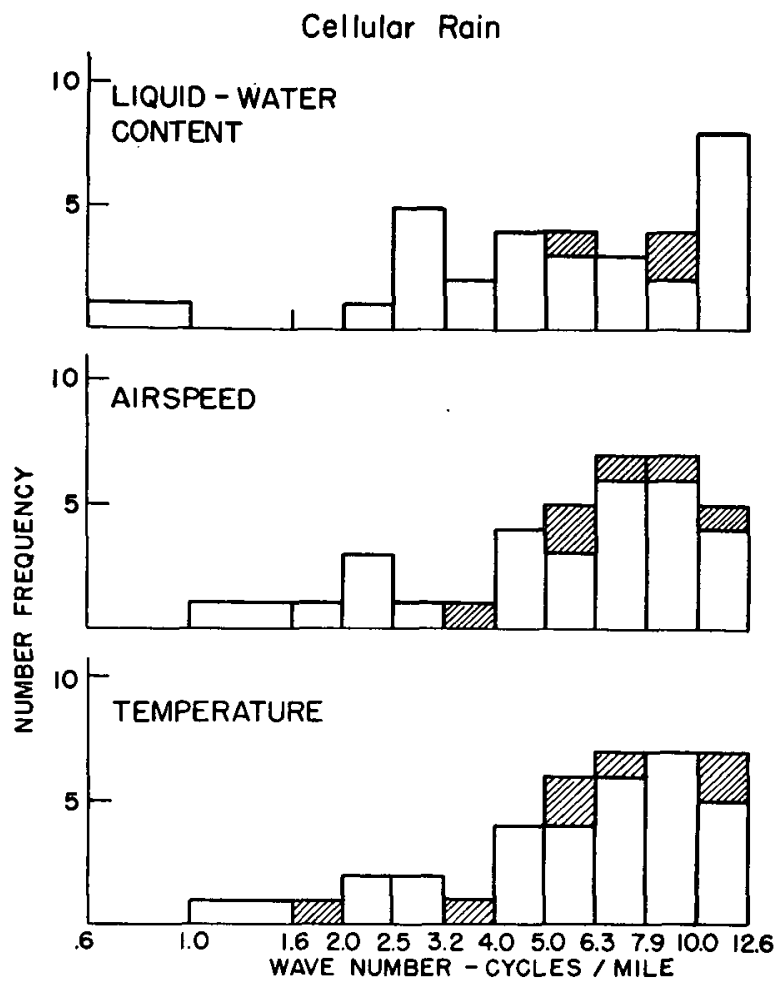

FIG. 5. Histograms showing number of spectra for cellular rain having a peak significant at the 10 per cent level in the specified interval of wave number. The hashed areas refer to two cases for which the spectra had low resolution $\left(0.4 \mathrm{cy} \mathrm{mi}{ }^{-1}\right)$ because of short traverse lengths. 
b) Cellular rain. The same modes were found among cellular rain cases but with less persistence. The spectral peaks in the longer wave regime again showed preference for wave numbers between 2 and $3 \mathrm{cy} \mathrm{mi}^{-1}$ for all three parameters. A preference for the shorter wave mode to occur between 5 and $6 \mathrm{cy} \mathrm{mi}^{-1}$ was only weakly indicated in liquid-water content spectra and the frequency mode was shifted toward shorter wavelengths in the airspeed spectra; once again peak positions in the temperature spectra occurred throughout the high wave numbers.

c) Stratus. The analysis of stratus cases was hampered by a small sample. Although two frequency domains were indicated in all the spectra, the wave numbers of the peaks were highly variable.

Thus, the histograms, as well as the individual spectra, suggest that there are two spectral regions within which the variance spectrum for a convective cloud series is likely to have a significant mode. Moreover, they show that in turbulent convection, and to a lesser extent in cellular rain, the location of peaks within these regimes is quite consistent except for temperature modes at high wave numbers.

The average relative contributions to the variance from each of the two spectral regions are shown in Table 2, along with the ratio of the contribution from the high wave number regime $b$ to that of the low wave number regime $a$. In considering the values shown in this table it must be realized that since they are relative, rather than absolute, contributions, cases with important trend and/or long wave components will show contributions in high wave numbers which are lower than those in cases without trend. Thus, the generally low contributions indicated for the temperature series are probably due to the existence of hurricane scale gradients which, along with navigational changes, may be responsible also for the low values indicated for the airspeed series. Liquid-water content on the other hand is a discontinuous parameter; the twofold differences between the relative contributions for convection and for cellular rain and stratus are probably indicative of the greater importance of the cloud-size components in the former.

It is clear from the ratios given in this table that the smaller wavelength regime $b$ is of greater importance

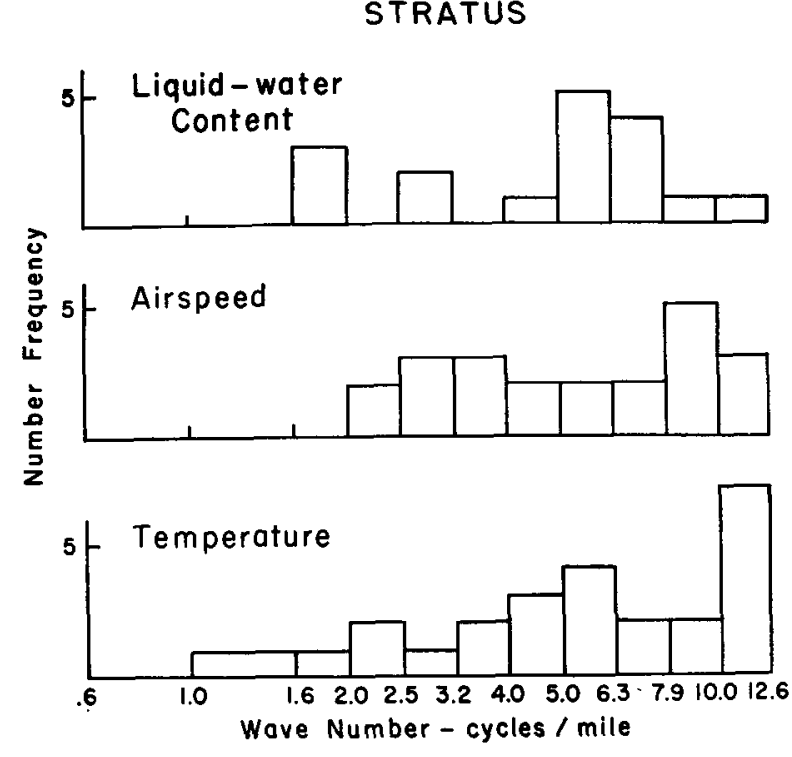

FIG. 6. Histograms showing number of spectra for stratus having a peak significant at the 10 per cent level in the specified interval of wave number.

(relative to that of the longer wavelengths) in cellular rain than in convective bands and of still greater importance in stratus. This is most striking in the case of temperature but is also quite regularly indicated for airspeed. For water content the relative importance of the two regimes is similar for convection and cellular rain but the smaller sizes are of increased importance in stratus.

\section{Discussion}

The results of the mathematical analysis carried out on the meteorological series from hurricane clouds showed that the variance spectrum tended to be divided into spectral regions within which one, and sometimes more than one, peak fell. The complexity of the spectra introduce certain problems of interpretation. In particular, the occurrence of multiple peaks raises the question as to whether some of them might not be harmonics of an elementary long wave component and a mathematical fiction rather than physical reality.

TABLE 2. Relative contributions (in per cent) to the variance from two wave regimes. The ratio $b / a$ gives the ratio between the contributions to the variance from the high wave number regime $b$ and the low wave number regime $a$.

\begin{tabular}{|c|c|c|c|c|c|c|c|}
\hline \multirow[b]{2}{*}{ Cloud type } & \multirow[b]{2}{*}{$\begin{array}{c}\text { Regime } \\
\left(k, \text { cy mi }{ }^{-1}\right)\end{array}$} & \multicolumn{2}{|c|}{ Liquid-water content } & \multicolumn{2}{|c|}{ Airspeed } & \multicolumn{2}{|c|}{ Temperature } \\
\hline & & $\begin{array}{c}\text { Relative } \\
\text { contribution }\end{array}$ & $\underset{b / a}{\text { Ratio }}$ & $\begin{array}{c}\text { Relative } \\
\text { contribution }\end{array}$ & $\underset{b / a}{\text { Ratio }}$ & $\begin{array}{c}\text { Relative } \\
\text { contribution }\end{array}$ & $\begin{array}{c}\text { Ratio } \\
b / a\end{array}$ \\
\hline $\begin{array}{l}\text { Convective } \\
\text { bands }\end{array}$ & $\begin{array}{l}\text { (a) } 1.8-4.5 \\
\text { (b) } 4.5-8.5\end{array}$ & $\begin{array}{r}12.8 \\
6.5\end{array}$ & 0.50 & $\begin{array}{l}5.3 \\
1.9\end{array}$ & 0.35 & $\begin{array}{l}5.5 \\
2.0\end{array}$ & 0.36 \\
\hline $\begin{array}{l}\text { Cellular } \\
\text { rain }\end{array}$ & $\begin{array}{l}\text { (a) } 1.9-4.7 \\
\text { (b) } 4.7-9.0\end{array}$ & $\begin{array}{l}25.8 \\
13.3\end{array}$ & 0.52 & $\begin{array}{l}5.5 \\
2.1\end{array}$ & 0.38 & $\begin{array}{l}5.7 \\
2.9\end{array}$ & 0.51 \\
\hline Stratus & $\begin{array}{l}\text { (a) } 2.1-4.7 \\
\text { (b) } 4.7-9.1\end{array}$ & $\begin{array}{l}25.7 \\
15.4\end{array}$ & 0.60 & $\begin{array}{l}4.0 \\
1.7\end{array}$ & 0.42 & $\begin{array}{l}3.1 \\
2.5\end{array}$ & 0.81 \\
\hline
\end{tabular}


Although it is difficult to rule out this possibility entirely, a suspected harmonic could usually be picked out in the original series. In addition, a group of test cases in which special band-pass filters were applied to the original series to isolate components also suggested that most of the statistically significant peaks were real and not mathematical harmonics.

Much of the complexity in individual spectra is believed to be due to non-stationarity in the data series on the scale of clouds or cells. That the cloud series may be non-stationary in space is more of a probability than a possibility. The assumption that the space distribution is constant over the short period of time covered by a traverse is probably good enough so that non-stationarity due to time change on that scale should not seriously affect the spectrum. However, clouds themselves are non-stationary on a much longer time scale; their history is one of change and the so-called steady state is short-lived. Any very large cloud of the class of cumulonimbi is known to be composed of two or more cells each of which undergoes a complete life cycle, not necessarily coincidental in time with any other one. That all parts of a smaller cloud, regardless of whether or not it can be divided into individual cells, are not in the same stage of development can be seen just by watching a small summer-time cumulus for 10-15 min.

In series through hurricane bands, which are arrays of cells, large and small, one must expect that the members of the array will be at different stages in their life history. Moreover, it seems reasonable that the smaller elements in a cloud or cloud cell, be they bubbles, jets, or plumes, may also be at different stages of their life cycle. The three parameters considered here are known to differ in clouds at various stages of their life cycle. Thus, one must conclude that these cloud series from hurricane bands are indeed non-stationary, i.e., that the mean, and/or variance, and/or spectrum probably changes through the series.

Series of measurements covering an array of clouds in a band is analogous to a natural splicing. The results of splicing studies, as well as recent studies in nonstationary time series (Granger and Hatanaka, 1964), indicate that the spectrum of a series through such an array is a close approximation to the average of the spectra of the individuals. Although averages usually tend to smooth, this proved not necessarily true in cases where the location of peaks differed by discrete amounts. It was found that the average of two or three spectra often contained all the peaks of the components, provided the shapes of the spectra were such that the peaks in one were not masked by ascending or descending limbs in another.

Despite the problems introduced by non-stationarity, the repeated occurrence of peaks at certain wave numbers increases the confidence with which the results can be accepted to well beyond the minimal 10 per cent level used for individual spectra. Indeed, considering the manner in which the data were collected, the degree of agreement in convective clouds (Fig. 4) was somewhat unexpected. Although the traverses were usually across the axis of the cloud band, the angle of crossing varied by 40 to $50 \mathrm{deg}$. Thus, there is a source of sampling variability which would be very pronounced if the eddies or "patches" were not circular and/or the cells or clouds occurred in certain patterns.

\section{Summary}

This study indicates that the fluctuations in meteorological parameters in clouds are ordered rather than random in the wavelength regime from about 200 to $1000 \mathrm{~m}$, and perhaps also to still smaller sizes. In this range, there appear to be two regimes, within which one or more modes of activity may occur. The upper one of these extends from wavelengths of about 900 to $350 \mathrm{~m}$ and the other between 350 and $180 \mathrm{~m}$. The smaller wavelengths tended to be a more important contributor to the variance (relative to the longer waves) in stratus than in cellular rain or convection.

Locations of peaks within these spectral regions were quite consistent in active convection and somewhat less in cellular rain. In the lower frequencies they were found between 2 and $3 \mathrm{cy} \mathrm{mi}^{-1}$ ( 550 and $800 \mathrm{~m}$ wavelength) for all three meteorological variables. In the shorter wavelengths peaks usually occurred between 5 or 6 cy mi ${ }^{-1}(250-300 \mathrm{~m})$ for water content and (to a lesser extent) airspeed; in the temperature measurements the location of modes within this region was highly variable.

Thus, the results suggest that in hurricane cloud bands significant patchiness occurs on dimensions smaller than cloud or cell size and, in particular, tends to occur on two scales, one around $700 \mathrm{~m}$ and another around $300 \mathrm{~m}$.

One may speculate on the physical processes which are behind these modes. It is suggested that the longer wavelength regime with mode preferentially between 600 and $800 \mathrm{~m}$ is thermal in origin. Once such an "eddy" is established, it may be expected to maintain itself in the water content and velocity fields beyond the lifetime of the initiating impulse. If the cellular rain cases represent dissipating convection the modal preference should be less pronounced in temperature than in the other parameters, as it was. Moreover, in stratus the importance of this regime as a contributor to the variance in temperature relative to other sub-cloud regimes should be much less, as is also observed.

The smaller scales $(200-300 \mathrm{~m})$ are believed to be non-convective turbulence modes induced by irregularities in the velocity and/or water fields. One may speculate also that they may be manifestations of small convective bubbles. However, the fact that the smaller sizes seem to be relatively more important in layer-type cloud seems to favor the first proposal over the second, 
TABLE 3. - - Scale sizes reported by number of researchera for a variety of meteorological parameter and phenomena

\begin{tabular}{|c|c|c|c|}
\hline Author & Phenomenon & Size & Remarka \\
\hline Byer \& Braham, 1949 & $\begin{array}{l}\text { Thunderstorms, } z=6000-26,000 \mathrm{ft} . \\
\text { Updraft width (most frequent) }\end{array}$ & $1500 \mathrm{~m}$ & Aircraft meanurement \\
\hline Curningham, 1958 & $\begin{array}{l}\text { Line of trade-wind cu congestua. } \\
\text { Humidity }\end{array}$ & $430 \mathrm{~m}$ & $\begin{array}{l}\text { Aircraft meanurement (one fight). } \\
\text { Measured from Fig. } 3 \text {. }\end{array}$ \\
\hline Elliott, et al, 1961 & $\begin{array}{l}\text { Pacific coast storm. } \\
\text { Water content. (Peak-to-peak spacing) }\end{array}$ & $900-1300 \mathrm{~m}$ & $\begin{array}{l}\text { Aircraft measurement. Recording } \\
\text { interval: } \sim 350 \mathrm{~m} \text {. }\end{array}$ \\
\hline Gray, 1964 & $\begin{array}{l}\text { Hurricane, } Z=10,000-20,000 \mathrm{ft} . \\
\text { Updraft and downdraft-combined width } \\
\text { (most frequent). }\end{array}$ & $960-2000 \mathrm{~m}$ & Aircraft measurement. From Fig. 23. \\
\hline Malkus, 1954 & $\begin{array}{l}\text { Trade cumulus. } \\
\text { Updraft width }\end{array}$ & $340-960 \mathrm{~m}$ & $\begin{array}{l}\text { Aircraft measurement ( } 2 \text { elouds). } \\
\text { From tables. }\end{array}$ \\
\hline Squires, $1958 \mathrm{a}$ & $\begin{array}{l}\text { Cumuli, } 5 \text { to } 7000 \mathrm{ft} \text { thick. } \\
\text { Droplet concentration and water content } \\
\text { (peak-to-peak apacing). }\end{array}$ & $400-800 \mathrm{~m}$ & $\begin{array}{l}\text { Aircraft measurement }(6 \text { casea }) \text {. } \\
\text { Recording interval: } \sim 200 \mathrm{~m} \text {. Inferred } \\
\text { from Table } 2 \text {. }\end{array}$ \\
\hline Steiner \& Rhyne, 1962 & $\begin{array}{l}\text { Severe storms, } Z=25,000-40,000 \mathrm{ft} \text {. } \\
\text { Vertical and horizontal gusta (spectral } \\
\text { peaks). }\end{array}$ & $30-200 \mathrm{~m}$ & $\begin{array}{l}\text { Aircraft measurements. Analysis } \\
\text { covers wave lengthe } 20-1100 \mathrm{~m} \text {. From } \\
\text { figures. }\end{array}$ \\
\hline $\begin{array}{l}\text { Weickmann \& } \\
\text { aufm Kampe, } 1953\end{array}$ & $\begin{array}{l}\text { Cumulus congestus. } \\
\text { Visibility }\end{array}$ & $300-500 \mathrm{~m}$ & $\begin{array}{l}\text { Aircraft measurement. Measured from } \\
\text { Fig. } 6(2 \text { cloud } \theta) \text {. }\end{array}$ \\
\hline Todd, 1964 & $\begin{array}{l}\text { Orographic cu congestus. } \\
\text { (a) Width of towers } \\
\text { (b) Updraft width }\end{array}$ & $\begin{array}{l}150-900 \mathrm{~m} \\
450-900 \mathrm{~m}\end{array}$ & $\begin{array}{l}\text { Photographic and airplane measurement. } \\
\text { two hours of observations. }\end{array}$ \\
\hline Glass Carlson, 1963 & $\begin{array}{l}\text { Small orographic cumuli. } \\
\text { Maximum diameters. }\end{array}$ & $300-1800 \mathrm{~m}$ & Photographic measurement. \\
\hline Malkua \& Scorer, 1955 & $\begin{array}{l}\text { 1solated cumulus bubbles ftrades and } \\
\text { mid-lat. } \\
\text { Width of bubbles. }\end{array}$ & $250.750 \mathrm{~m}$ & $\begin{array}{l}\text { Photographic measurement (13 cases). } \\
\text { From tables. }\end{array}$ \\
\hline Saunder8, 1961 & $\begin{array}{l}\text { Large isolated towers (high latitudes). } \\
\text { Width of towers (average). }\end{array}$ & $1200 \mathrm{~m}$ & $\begin{array}{l}\text { Photographic measurement }(11 \text { cases }) \text {. } \\
\text { From tables. }\end{array}$ \\
\hline Fleisher, 1957 & $\begin{array}{l}\text { Light snow, } z=0.5-1.5 \mathrm{~km} \\
\text { Horizonta) wind (spectral peak). }\end{array}$ & $600 \mathrm{~m}$ & $\begin{array}{l}\text { Doppler radar measurement. Variance } \\
\text { spectra shown in Fig. 1. }\end{array}$ \\
\hline Bunker, 1962 & $\begin{array}{l}\text { Sub-cloud layer, trades. } \\
\text { Humidity (spectral peaks). }\end{array}$ & $700-2000 \mathrm{~m}$ & $\begin{array}{l}\text { Aircraft measurement. Spectra for } \\
\text { wave lengths }>700 \mathrm{~m} \text {. From Figs. } 10-13 \text {. }\end{array}$ \\
\hline James, 1953 & $\begin{array}{l}\text { Sub-cloud layer, mid-latitudes. } \\
\text { Diameters of warm cores: } \\
\text { (a) } \mathrm{Z}=150-300 \mathrm{~m} \\
\text { (b) } \mathrm{Z}=300-750 \mathrm{~m}\end{array}$ & $\begin{array}{l}150-1200 \mathrm{~m} \\
150-300 \mathrm{~m}\end{array}$ & Aircraft measurement (one night). \\
\hline Warner \& Telford, 1963 & $\begin{array}{l}\text { Sub-cloud layer; varying terrain. } \\
\text { (a) Thermal structure } \\
\text { (b) Vertical velocity }\end{array}$ & $\begin{array}{l}\text { Few hundred meters } \\
\text { Eot. } 450-800 \mathrm{~m}\end{array}$ & $\begin{array}{l}\text { Aircraft measuremente. Thermal } \\
\text { structure from text. Velocity modes } \\
\text { from Fig. } 1 .\end{array}$ \\
\hline .Charnock, et al, 1957 & $\begin{array}{l}\text { Wind atructure in trades, } z<1500 \mathrm{~m} \text {, } \\
\text { (a) Thickness of buoyant bubbles } \\
\text { (b) Scale of horizontal turbulent flow }\end{array}$ & $\begin{array}{l}400 \mathrm{~m} \\
500 \mathrm{~m}\end{array}$ & Double theodolite measurements. \\
\hline Davenport, 1961 & $\begin{array}{l}\text { Horizontal gustuness in high winds; } \\
\mathrm{Z}=12-150 \mathrm{~m} \\
\text { (a) Various mid-1at, storms } \\
\text { (b) Hurricanes, N. Y. } \\
\text { (Bpectral peaks) }\end{array}$ & $\begin{array}{l}400-600 \mathrm{~m} \\
250-550 \mathrm{~m} \\
\text { (both increasing } \\
\text { with } 2 \text { ) }\end{array}$ & $\begin{array}{l}\text { Tower measurement from Auetralia, } \\
\text { England, New York and Mich, }\end{array}$ \\
\hline Lappe \& Davidson, 1960 & $\begin{array}{l}z=120-300 \mathrm{~m} \\
\text { Vertical velocities (opectral peaks) }\end{array}$ & $\begin{array}{l}400-650 \\
200-300 \mathrm{~m}\end{array}$ & $\begin{array}{l}\text { Aircraft and tower measurements. } \\
\text { From figures. }\end{array}$ \\
\hline $\begin{array}{l}\text { Panof sky \& McCormick, } \\
1954\end{array}$ & $\begin{array}{l}z=23-100 \mathrm{~m} \\
\text { Vertical velocity (spectral peaks) } \\
\text { (a) Unstable conditions } \\
\text { (b) Max. instability } \\
\text { (c) Division between mechanical and } \\
\text { convective turbulence }\end{array}$ & $\begin{array}{l}150-600 \mathrm{~m} \text { (inc. } \\
\text { with height) } \\
450-800 \mathrm{~m} \\
\sim 200 \mathrm{~m} \text { (at } z=90 \mathrm{~m} \text { ) }\end{array}$ & Tower measurements. \\
\hline $\begin{array}{l}\text { Panof } 8 k y \text { \& McCormick, } \\
1960\end{array}$ & $\begin{array}{l}Z=2 \mathrm{~cm} \text { to } 600 \mathrm{~m} \\
\text { Vertical winds (spectral peaks) } \\
\text { (a) Surface to } 100-200 \mathrm{~m} \\
\text { (b) } \mathrm{Z}=200-600 \mathrm{~m}\end{array}$ & $\begin{array}{l}\sim 42 \\
600-900 \mathrm{~m}\end{array}$ & Tower and airplane data. \\
\hline Smith, $196 \mathrm{t}$ & $\begin{array}{l}z=150-650 \mathrm{~m} \\
\text { vertical wind (spectral peaks) }\end{array}$ & $1100 \mathrm{~m}$ & $\begin{array}{l}\text { Meagurement along ceptive balloon } \\
\text { cable. Average for } 18 \text { cases given in } \\
\text { Table 1. }\end{array}$ \\
\hline Van der Hoven, 1957 & $\begin{array}{l}\text { Hurricane, } Z=100 \mathrm{~m} \\
\text { Horizontal wind (spectral peak). }\end{array}$ & $900 \mathrm{~m}$ & Tower measurement. From Fig. 1 . \\
\hline
\end{tabular}


particularly if the cellular rain and stratus clouds were indeed the remains of older convective areas.

This study of sub-cloud scales in hurricane clouds was approached as a study of clouds in general and only incidently as clouds in a specific kind of disturbance. It was necessary to confine the calculations to hurricane cloud areas because only these satisfied the needs of the analysis technique as to series length. Experience with both qualitative and quantitative studies of a variety of convective cloud types, suggests that, with regard to sub-cloud scales at least, the hurricane clouds do not differ in general detail from other convective clouds.

The literature yields information of the dimensions or spacing of a variety of parameters, either in specific studies of size or in figures and tables included in studies of other kinds. Some of these reports in the scale of micro-mesometeorology are listed in Table 3. At first glance there may seem great scatter in cited dimensions; closer perusal shows less than might be expected.

In eight of the thirteen cloud studies the sizes fell largely in the range of the long wave spectral region found in this study, i.e., between 350 and $900 \mathrm{~m}$. One of the other five (Steiner and Rhyne, 1962) was confined to smaller scale turbulence in severe storms and reported sizes only slightly smaller than that of the "turbulent" mode found in the hurricane data.

There is less agreement among the three sub-cloud layer studies but it should be noted that Bunker (1962) did not consider wavelengths of less than $700 \mathrm{~m}$. The data from Warner and Telford (1963) again indicate sizes in the "long wave" regime.

The connection between hurricanes and wind conditions in the friction layer may seem remote. However, one cannot help being impressed by the frequency with which scales in the range of 400 to $800 \mathrm{~m}$ are cited in the turbulence literature (last seven papers). Of particular interest perhaps are the wavelengths of the spectral peaks (estimated from frequency) found by Davenport (1961) and Van der Hoven (1957) in wind records for hurricanes which had moved over the northeastern part of the United States.

The reader's attention is also directed toward a recent paper by Reiter and Burns (1966) in which the velocity spectra from clear air turbulence measurements at about $30,000 \mathrm{ft}$ show peaks at wavelengths of about $300 \mathrm{~m}$ (but not at wavelengths of 700 or $800 \mathrm{~m}$ ) for cross-wind flights in thermally stable regions:

Considering the range of phenomena, meteorological parameters, types of observations, and analysis, the amount of agreement between these reports is surprising. Surprising too is the agreement with the size of the graininess or patchiness found for the various parameters in hurricane clouds. The idea that there may be a scale which the atmosphere "prefers" is a provocative one. But can the seeming uniformity just be coincidence?

Acknowledgments. The author wishes to express her thanks to Prof. Horace R. Byers for his advice and encouragement and to acknowledge with gratitude the assistance of a number of employees and student technicians of the Cloud Physics Laboratory who did the extensive data reduction required by this study. She would also like to express her appreciation to $\mathrm{Mr}$. Robert Cecil Gentry and the staff of the National Hurricane Research Project for their cooperation and help.

\section{REFERENCES}

Ackerman, B., 1963 : Some observations of water contents in hurricanes. J. Atmos. Sci., 20, 288-298.

Blackman, R. B., and J. W. Tukey, 1958: The Measurement of Power Spectra. New York, Dover Publ., Inc., 190 pp.

Braham, R. R., Jr., and E. A. Neil, 1957: Hurricane cloud physics research. Univ. of Chicago, Cloud Physics Lab., Final Report, Contract Cwb-8714, $55 \mathrm{pp}$. (Clearinghouse for Fed. Sci. Info., PB-165151, \$7.60).

Bunker, A. F., 1962: Water vapor distribution in the sub-cloud trade wind air. Woods Hole Oceanogr. Inst., Tech. Rep. No. 47 (Ref. No. 62-2), 44 pp. (Clearinghouse for Fed. Sci. Info., AD-271636, \$6.60.)

Byers, H. R., and R. R. Braham, Jr., 1949: The Thunderstorm. Washington, U.S. Govt. Printing Office, $287 \mathrm{pp}$.

Charnock, H., J. R. D. Francis and P. A. Sheppard, 1957: An investigation of wind structure in the Trades: Anegada 1953. Phil. Trans. Roy. Soc., London, A249, 179-234.

Cunningham, R. M., 1958: Cumulus circulation. Recent Advances in Atmospheric Electricity, New York, Pergamon Press, 361-367.

Davenport, A. G., 1961: The spectrum of horizontal gustiness near the ground in high winds. Quart. J.R. Meteor. Soc., 87, 194-211.

Elliott, R. D., E. L. Hovind and J. W. Flavin, 1961 : Investigation of cloud water budget of Pacific Storms. North American Weather Consultants, Goleta, Calif., Final Report NSF Contract C-104, 54 pp. (Clearinghouse for Fed. Sci. Info., P.B. 170-510, Microfiche at \$.75.)

Fleisher, A., 1957: Some spectra of turbulence in the free atmosphere. Dept. of Meteor., Cambridge, Mass. Inst. of Tech., Res. Rep. No. 31, 4 pp. (Clearinghouse for Fed. Sci. Info., AD 161-849, \$1.10.)

Gilman, D. L., F. J. Fuglister and J. M. Mitchell, 1963: On the power spectrum of "red noise." J. Atmos. Sci., 20, 182-184.

Glass, M., and T. N. Carlson, 1963: The growth characteristics of small cumulus clouds. J. Atmos. Sci., 20, 397-406.

Granger, C. W. J., and M. Hatanaka, 1964: Spectral Analysis of Economic Time Series. Princeton, N. J., Princeton Univ. Press, 299 pp.

Gray, W. M., 1964: On the scales of motion and internal stress characteristics of the hurricane. Ph.D. Thesis, Dept. of Geo. Phys. Sci., Univ. of Chicago, 186 pp.

James, D. G., 1953: Fluctuations of temperature below cumulus clouds. Quart. J. R. Meteor. Soc., 79, 425-428.

Lappe, U. O., and B. Davidson, 1960: The power spectral analysis of concurrent airplane and tower measurements of atmospheric turbulence. College of Eng., New York, New York Univ., Final Rep. Contract No. NOas 58-517-d, 36 pp. (Clearinghouse for Fed. Sci. Info., AD 251-055.)

Malkus, J. S., 1954: Some results of a trade-cumulus cloud investigation. $J$. Meteor., 11, 220-237.

, and R. S. Scorer, 1955: The erosion of cumulus towers. J. Meteor., 12, 43-57.

Panofsky, H. A., and R. A. McCormick, 1954: Properties of spectra of atmospheric turbulence at 100 meters. Quart. J. R. Meteor. Soc., 80, 546-564.

- - and -1960 : The spectrum of vertical velocity near the surface. Quart. J. R. Meteor. Soc., 86, 495-503. 
Reiter, E. R., and A. Burns, 1966: The structure of clear-air turbulence derived from "TOPCAT" aircraft measurements. J. Atmos. Sci., 23, 206-212.

Saunders, P. M., 1961: An observational study of cumulus. $J$. Meleor., 18, 451-467.

Smith, F. B., 1961: An analysis of vertical wind fluctuations at heights between 500 and 5,000 ft. Quart. J. R. Meleor. Soc., 87, 180-193.

Squires, P., 1958: The spatial variation of liquid water content and droplet concentration in cumuli. Tellus, 10,372-380.

Steiner, R., and R. H. Rhyne, 1962 : Some measured characteristics of severe storm turbulence. Nat'l. Sev. Storms. Proj., Washington, U. S. Wea. Bureau, Rep. No. 10, 17 pp. (Clearinghouse for Fed. Sci. Info., N62-16401, \$2.00.)

Todd, C. J., 1964: Aircraft traverses in a growing mountain cumulus cloud. $J$. Atmps. Sci., 21, 529-538.

Tolefson, H. B., 1945: Airspeed fluctuations as a measure of atmospheric turbulence. Nat'l. Advisory Committee for Aeronautics, Washington, Advanced Restricted Rep. No.
L5F27, 10 pp. (Clearinghouse for Fed. Sci. Info., PB-94281, Ph. $\$ 2.50$.)

Tukey, J. W., 1949: The sampling theory of power spectrum estimates. Symposium on applications of autocorrelation analysis to physical problems. Office of Naval Res., Washington, Dept. of the Navy, NAV EXOS-P-735, 47-67. (Clearinghouse for Fed. Sci. Info., PB-105341, Ph.-\$11.25.)

Van der Hoven, I., 1957: Power spectrum of horizontal wind speed in frequency range from 0.0007 to 900 cycles per hour. J. Meteor., 14, 160-164.

Ward, F., and R. Shapiro, 1961: Meteorological periodicities. J. Meteor., 18, 635-656.

Warner, J., and T.D. Newnham, 1952: A new method of measurement of cloud-water content. Quart. J. R. Meteor. Soc., 78, 46-52.

—_, and J. W. Telford, 1963 : Some patterns of convection in the lower atmosphere. J. Atmos. Sci., 20, 313-318.

Weickmann, H. K., and H. J aufm Kampe, 1953 : Physical properties of cumulus clouds. $J$. Meteor., 10, 204-211. 